skin fills the site of the abdominal wound. In regard to the treatment of the pedicle, I hope that in most cases some intra-peritoneal method may be found, perhaps by burning with the cautery. No rule can be made at present, however, and each case must be treated independently.

\section{SOME CLINICAL OBSERVATIONS IN REGARD TO MONO-CHOREAS ASSOCIATED WITH INCREASED TEMPERATURE OF THE PART AFFECTED.}

BY hOBART AMORY hARE, M.D. (UNIV. OF PA.),

Attending Physician to the Children's Dispensary of the Aniversity Hospital of Philadelphia.

The following cases are reported in order to call attention to what seems to be quite a common occurrence in mono-choreas, namely, an increase in the temperature of the member or part affected. So far as I know, such changes in temperature in this disease have not been reported; although, as every one knows, it is quite common in hemichoreas to have a decrease in temperature of the side affected, accompanied generally by profuse perspiration. In the cases here reported the member affected was invariably hot, dry, and feverish. The color of the skin was more red than normal, the skin also had rather an injected appearance.

The coldness of the parts in hemi-chorea is probably due to some neurosis affecting the blood-supply and also to the constant evaporation of the perspiration, which is caused probably by some disorder connected intimately with the nerves governing the sweat-glands. It is entirely permissible to account for the increase of temperature noted in these cases by supposing that the neurosis may be such as to cause the contrary effect of that mentioned in regard to the coldness of the parts, namely, an increased supply of the arterial blood instead of a decreased supply. There is a possibility that this increase of temperature may be due to the constant muscular movements peculiar to the disease, but this is very improbable, since the heat developed by the movements in so few muscles would not be appreciable. It seems to me that the redness and injection of the skin point to the conclusion that the difference in temperature between the affected and unaffected members is due to the inordinate supply of arterial blood in the part. In one or two cases it was impossible to find the temperature of the part by the thermometer, since the hand was often hot and feverish and the axilla normal. As the thermometer used was the one commonly in use at the bedside, it was impossible to take the temperature of the palmar surfaces.

Case I. Katy Burns, aged eight, came to the Dispensary of the Children's Hospital ${ }^{1}$ of this eity, suffering from a mono-chorea of the left arm. The child appeared strong and in good health, although the face was perhaps lacking in color. The mother stated that about one week previously she had noticed this peculiar and constant twitching of the arm, which kept up night and day, and had first

1 I am able to mention this case through the kindness of Dr. Louis Starr, the physician in charge of the Dispensary at the time the patlent presented herself. ascribed it to " fidgetyness" but had found that it could not be controlled by the will. The child has never had scarlet fever, diphtheria, or rheumatism. She had measles some years ago, but made a good and rapid recovery. On examining the hand and arm they were found redder than normal and the skin was dry, hot, and feverish. The temperature of the right axilla was $98.4^{\circ}$, while that of the left axilla was $99.8^{\circ}$, an increase of $1.4^{\circ}$ over the normal side. The heat was normal, the appetite good, and the bowels regular. This case recovered entirely in the course of four weeks, receiving three drops of Fowler's solution three times a day during that space of time. There is no difference between the two axillæ at this writing and the reddened appearance of the skin has disappeared, the two arms and hands having the same hue.

Case II. Peter F., aged twelve, came to the Children's Dispensary of the University Hospital last fall, suffering with left brachial mono-chorea of a moderate type. Had a history of scarlet fever just preceding the choreic attack, which come on during convalescence : at least it was first noticed about this time by the parents. His heart was normal and his appetite generally quite good. His bowels were regular. There is a history of rheumatisin in the family, although the boy seems never to have been a sufferer from it in any degree whatsoever. His condition was fair and there was very little, if any, anæmia present. At that time he was put on Fowler's solution, and is still taking it, as he has not entirely recovered the control of his arm when certain movements are desired. As there seemed to be some slight loss of power he was given in addition to the Fowler a small amount of struchnia, about the fortieth of a grain, four times a day. When first examined there was a great deal of difference in temperature between the two arms and hands, the left hand feeling hot to the touch while the right was normal. The temperature in the axillæ was $99^{\circ}$ and $98.4^{\circ}$ respectively. The difference between the axillæ to the touch was scarcely noticeable, while, as already stated, the difference of temperature to the touch at the hands was marked. At present there is not much difference between the two members and the movements are not as severe as formerly, although it is doubtful whether they will ever cease entirely under his present mode of living and owing to the obstinacy of the disease in resisting treatment for so long time. The fact that the chorea followed scarlet fever would also point to an unfavorable prognosis. I forgot to mention that the affected arm in this case was also redder than normal.

Case III. Lizzie D., aged ten, two years ago had an attack of scarlet fever from which she entirely recovered. During the stage of desquamation, however, the mother noticed that her right arm was beginning to twitch, and by the time she was up and about, the choreic movements had become quite severe. During the last two years the movements have been constant, being somewhat less severe at night than during the day, and varying in intensity at different seasons, as in the spring for example. There is no history of paralysis following the attack of scarlet fever nor is there any history of rheumatism. The heart sounds are 
normal, the appetite is good, and the bowels slightly constipated. The movements are increased if spoken of in her presence. The possibility of any reflex irritation owing to intestinal worms was dispelled by the administration of male fern, chenopodium, and injections of turpentine and sweet oil. There is no history of masturbation or other genital irritation of any kind. No history of fright or chorea prior to the scarlatinous attack. No anæmia. The girl would generally be considered strong and sturdy and does not appear to be of a markedly nervous temperament. 'The hand and arm affected (the right) were warmer than the left. 'This difference was only appreciable by the touch, since the thermometer in the axillæ marked the same number of degrees in both cases. The right hand was hot, dry, and feverish, although the weather was cold and the child had come some distance. This case also recovered under the use of arsenic, the red hue of the hand and arm gradually disappearing as the patient's condition improved.

Case IV. George N., aged thirteen, came to the Dispensary of the University Hospital suffering from an irregular form of chorea, which, at times, affects the whole body, but which is constantly present to a slight degree in the right arm, from which point the movements extend when he is suddenly frightened or greatly excited, as by the sight of a runaway horse or something of a similar character. The arm does not appear to be much warmer than normal unless the movements are about to extend to the rest of the body, when the boy will say to his parents, "It's coming, my hand is getting hot," and within the next few minutes the general attack comes on.2 That this attack is not epileptic is shown by the fact that there is never loss of consciousness or frothing at the mouth. He keeps on saying what he wishes to say as if nothing was occurring, although his mother tells me that his words are not articulated clearly, owing to the movements affecting the muscles of his mouth. He never falls down during an attack and goes on with his work (sewing rag carpet) after the attack passes off as if nothing had occurred, although he is entirely conscious of his having had one. If asked a question during an attack he will invariably give a clear and lucid answer. The beginning of this trouble dates back six years. At that time, while at Atlantic City, he was forced by his parents to take a surf-bath although he was much averse to it, owing to fright. He no sooner reached the water than his kicking and screaming was replaced by rigidity. 'This alarmed the parents and they immediaely took him out and dressed him. After a few hours the child seemed perfectly well. In the course of the next few weeks the mother noticed a slight twitching of the eyelids, chiefly affecting the left side. This was so slight that the father denied its presence. This, however, passed away at the approach of winter. The following spring the movements appeared in the right arm, and from this point have annually made further inroads on the rest of the system till the present condition has been reached. During the summer, when he is out of town, he becomes almost

${ }^{2}$ The mother says that the hand feels hot to the touch and that the boy knows the approach of the attack, not by any change of feeling in the affected arm, but by the feeling which is conveyed to the normal hand of increased heat when the affected hand is grasped. entirely well. Sometimes the attacks come on without apparent cause, generally in such cases following several days of unusual quietude. One of the frequent causes of a general attack is an imperative eall, on the part of his father, to get up in the morning. The boy has improved slightly under the use of arsenic and tonics. He, however, is in every way, but that mentioned, healthy, strong, wellgrown, and the possessor of a good digestion and appetite.

This case, although not that of an ordinary chorea, is very interesting; as showing the change of temperature which takes place just before and during the movements of the arm, which seems to be the focus of each attack.

Case V. Robert P., aged nine. Came to the Dispensary suffering from a constant and incessant chronic movement of the eyelids. ${ }^{3}$ To all appearance he is a strong, healthy boy and not of a neurotic temperament. He is only a little pale and would not be regarded as anæmic. His mother states that last fall he had an attack of scarlet fever and this trouble came on during convalescence. The closest questioning fails to elicit any history of paralysis, or of this disease in any form prior to the attack of scarlet fever just mentioned. There are no abnormalities about the heart and there is no history of rheumatism. The appetite is good and so is digestion. The bowels are in good order. The eyelids, particularly the upper lids, are infected, redder than normal, hot and feverish to the touch. The boy also states that his "eyes feel hot," referring to the lids. 'There is no change in the eyes themselves, either in the manner of moving the ball or change of the pupil. Unfortunately the actual temperature could not be taken owing to the exposed position of the parts.

The treatment of this case consisted in the administration of Fowler's solution, the child recovering in about three weeks.

\section{Irepartg of Sacietieg.}

\section{SUFFOLK DISTRICT MEDICAL SOCIETY.}

SECTION OF OBSTETRICS AND GYNACOLOGY. ROBERT B. DIXON, M.D., SECRETARY.

February 18, 1885. Dr. James R. Chadwick in the chair.

Dr. John Homans read a paper entitled

TEN CASES OF REMOVAL OF UTERINE TUMORS BY LAPAROTOMY.

DR. J. W. Elliot remarked that the reader was especially to be congratulated on his success in the last case mentioned. For other operators had found the mortality very high in this class of cases, that is, cases where the tumor grows more or less from the cervix and extends into the broad ligament.

Dr. Homans's conclusions in regard to the intraperitoneal treatment of the stump were of interest because they were opposed to the conclusions one would draw from the statistics of other operators. In ovariotomy the pedicle was at first treated by

3 This case is hardly one of mono-chorea, and is mentioned here merely because the movements were localized and accompanied by increase of temperature. 